IP Periodica Polytechnica Civil Engineering

62(4), pp. 851-857, 2018

https://doi.org/10.3311/PPci.11343

Creative Commons Attribution (i)

\section{Wind and Tide-Induced Hydrodynamics and Sedimentation of Two Tidal Inlets in Western Greece}

\author{
Nikolaos Th. Fourniotis ${ }^{1,2 *}$, Georgios M. Horsch ${ }^{1}$, \\ Georgios A. Leftheriotis ${ }^{1}$ \\ Received 03 August 2017; Revised 02 January 2018; Accepted 27 March 2018
}

\begin{abstract}
To quantify the detailed mechanisms that cause sedimentation at the tidal inlets in the Messolonghi-Aetoliko lagoonal system, the MIKE 21 FM (HD \& ST) numerical simulation models were applied. The study focuses on the hydrodynamic circulation in the vicinity of the tidal inlets and the associated wind and tide-induced currents, as well as sediment transport, bed level evolution and total sediment load accumulation, with emphasis on the vicinity of two tidal inlets, where the problem is more acute. Based on the numerical predictions, which have been qualitatively corroborated via satellite images from Google Earth, it is shown that under the prevailing winds and tidal action, sandbars are formed in front or behind the tidal inlets depending on the wind direction, resulting in a gradual decrease of the mean water level at the mouths. Under the combined action of the tide and the wind the characteristic horizontal structure of the flow includes cyclonic and anticyclonic eddies that form at the near tip area of the jetties, which are associated with sediment transport mechanisms.
\end{abstract}

\section{Keywords}

hydrodynamics, sediment transport, tidal inlet, lagoon

\section{Introduction}

The Messolonghi lagoon, situated in Western Greece and located at $\mathrm{N} 38^{\circ} 22^{\prime}-\mathrm{E} 21^{\circ} 21^{\prime}$, is the largest wetland in Greece and one of the largest and most important in Europe, both in ecological and in economic terms. Lagoon's waters are shallow and open in the south to the waters of the Gulf of Patras (hereafter 'Gulf'). The depth ranges from a few $\mathrm{cm}$ in the interior regions, up to roughly $2.5 \mathrm{~m}$, while the mean depth is approximately 0.5 $\mathrm{m}$. The lagoon is separated from the Gulf's waters by approximately a $12 \mathrm{~km}$ long sand bar, oriented in the east-west direction (A, B, Fig. 1). The Lagoon ecosystem consists of a central part, i.e. the central lagoon, and a series of peripheral lagoons including Kleisova, Diavlos, Aitoliko, Tholi, Paleopotamos.

Each of the lagoons mentioned above communicates with the Gulf's open waters via tidal inlets, formed along the lagoon's sandy barrier (Fig. 1). Important fishing activities at the lagoon ecosystem are developed in these sites, including the tidal inlets of the lagoon along the barrier zone. These tidal inlets of the lagoon are the most dynamic area for water circulation and suspended sediment transport [1] [2]. The water exchange and sediment flux through the inlets govern the hydrodynamic and geomorphologic characteristics, as well as the physicochemical water properties, which are important for the maintenance of the lagoon ecosystem.

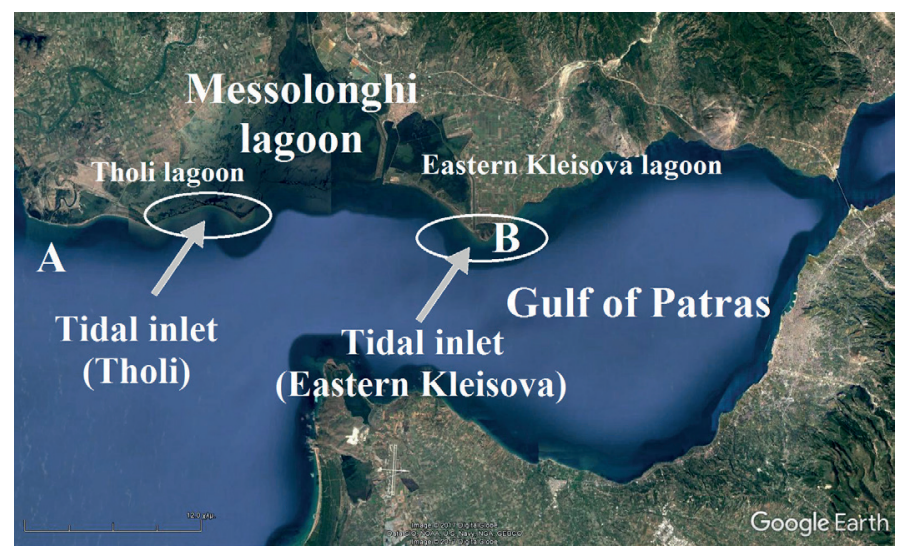

Fig. 1 Wider area of the Gulf of Patras and the Messolonghi lagoon, with the

\footnotetext{
peripheral lagoons Tholi and Eastern Kleisova as well as the corresponding tidal inlets, as seen from Google Earth (Google Earth, 2017 [9])
}

\footnotetext{
1 Department of Civil Engineering

University of Patras

University Campus, Patras, Greece

2 Department of Civil Engineering

Technological Educational Institute of Western Greece

Megalou Alexandrou 1, Patras, Greece.

* Corresponding author, email: nfou@upatras.gr
} 
One of the major threats to the Messolonghi lagoon is the gradual shoaling of the tidal inlets, which allow water exchange between the lagoon and the Gulf of Patras, due to coastal sediment accumulation that would eventually lead to the sealing off of these inlets. To maintain and protect the tidal inlets from coastal sediment accumulation, jetties have been constructed east and west of each tidal mouth. These jetties have helped to maintain the tidal inlets, but their presence lead to an undesirable shore line deformation and bed evolution, causing coastal erosion or accretion and moving the coastline forward, while there is still significant accumulation of sediment in front of the tidal mouths leading to gradual shoaling.

The proper management of the Messolonghi Lagoon, which is of primary importance to local fishermen, includes understanding of the causes of sedimentation in the tidal mouths, in order to plan the dredging operations or other works in the area. In a previous work [3], Fourniotis et al. studied the longshore sediment transport as well as the coastline (shoreline) evolution with emphasis on the vicinity of two tidal inlets, where the problem is more acute, namely Eastern Kleisova and Tholi. In the present work our aim is to understand the hydrodynamics of these complex openings, as well as to quantify the detailed mechanisms that cause sedimentation in front and inside of the tidal mouths and the time scale of the problem of sedimentation. To this end, we applied the MIKE 21 FM (HD \& ST) numerical simulation models [4] [5] [6], [7] in order to study the hydrodynamic circulation in the vicinity of the tidal inlets, the associated wind and tide-induced currents, as well as sediment transport, bed level evolution and total sediment load accumulation. Emphasis was given on the vicinity of the Eastern Kleisova and the Tholi peripheral lagoons' tidal inlets, of the Messolonghi lagoon ecosystem.

\section{The study area - existing formation}

The study area is a quasi-uniform sandy coast characterized by a rather mild slope and a semidiurnal mean tidal range of about $40 \mathrm{~cm}$. Under the locally prevailing winds in the Gulf and the combined action of the tide, strong wind-induced currents are generated at the nearshore region, in front of Messolonghi lagoon, the direction of which is dictated by the wind action, while in the central body of the Gulf the flow is mainly dictated by the tidal action [10] [11] [12].

The bathymetry is rather uniform, as shown in charts from the Hellenic Navy Hydrographic Service, with a relatively constant slope at the foreshore where isobaths are mostly parallel to the coastline. The presence of jetties east and west of each tidal mouth has disturbed the sediment budget of the coast. Specifically, accumulation of sediment was observed in the region westwards of the jetties, while eastwards longshore sediment transport has caused severe erosion and a gradual retreat of the coastline, as shown in Fig. 2.
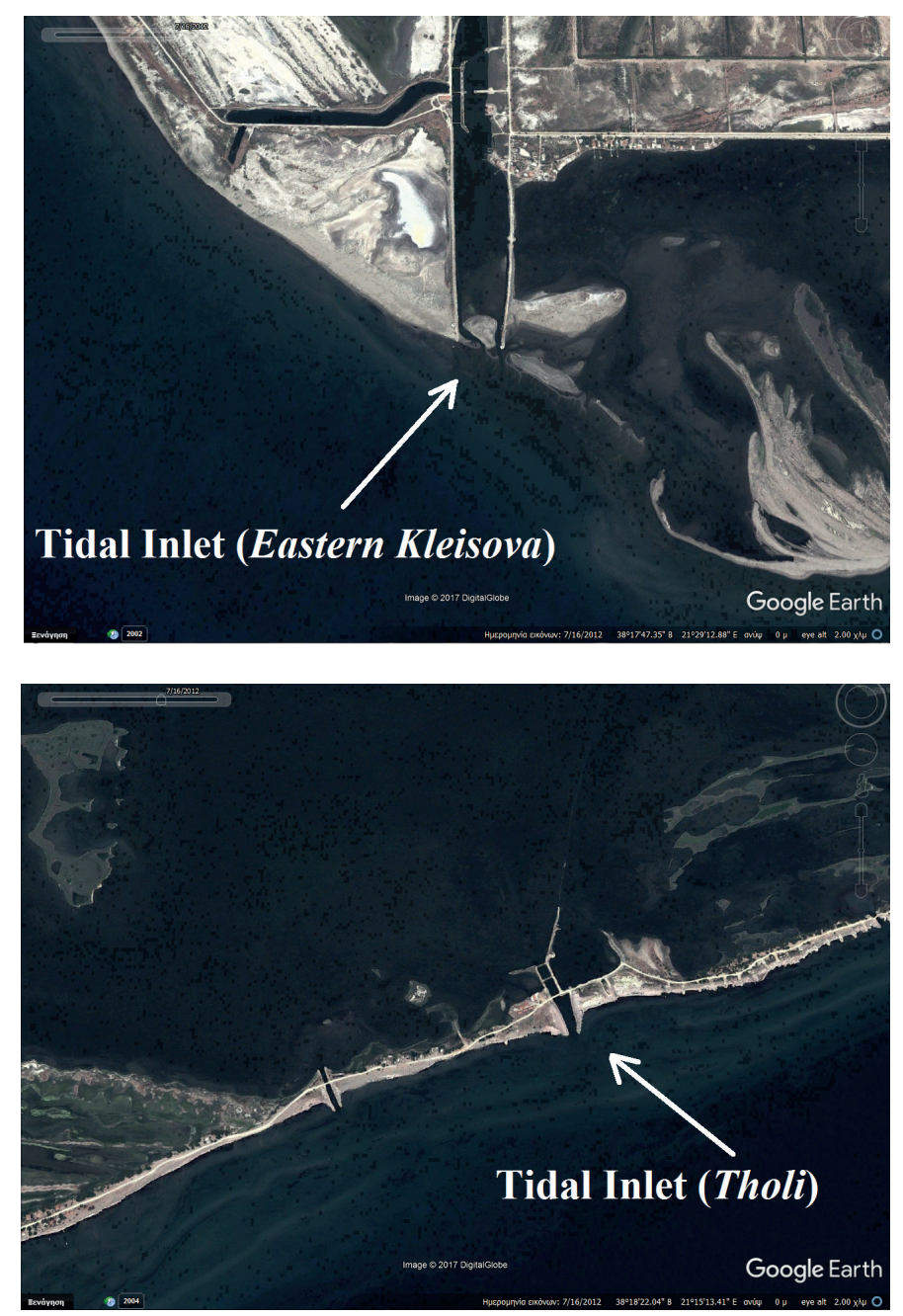

Fig. 2 Existing formation of tidal inlets with jetties (upper) Eastern Kleisova, (lower) Tholi, as seen from Google Earth [9]

Moreover, part of the total longshore transported sediment accumulates in front and inside of the tidal inlets affecting the operations of the lagoon's mouths. Thus, the water depth becomes shallow and the exchange flow is impeded. In Fig. 3, the formation of a sandy islet under the local hydrodynamics is given for the Eastern Kleisova tidal inlet.

In a previous study [3] the effect of wind waves in creating wave-induced currents was examined, in order to estimate the dynamics of longshore sediment transport. The aim of that study was to elucidate the prevailing direction of the net littoral transport of non-cohesive sediment, to estimate the annual rate of net and gross sediment transport along the coastline, to calculate the net and gross annual drift and finally to simulate the coastline evolution in the presence of jetties. Specifically, it was shown that the littoral transport at the northwestern coasts of the Gulf, i.e. in the vicinity of Eastern Kleisova and Tholi, reaches rates of the net drift of the order of $2000 \mathrm{~m}^{3} /$ year and $1500 \mathrm{~m}^{3} /$ year, respectively, directed from westward to eastward. That study was based on the fact that longshore currents are dominated by wave-driven currents with tidal and wind-induced currents being of lesser importance in that direction. Tidal and wind-induced flow may create, however, cross-shore currents 


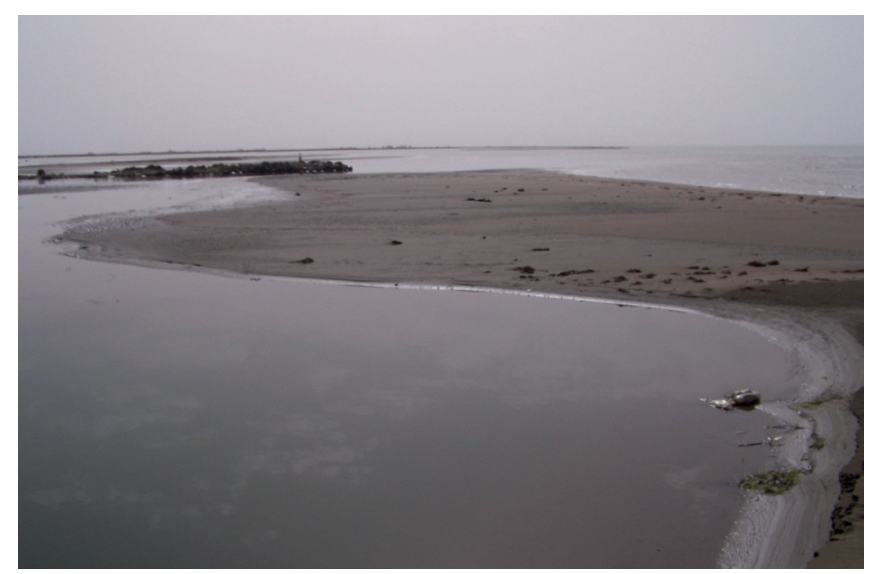

(a)

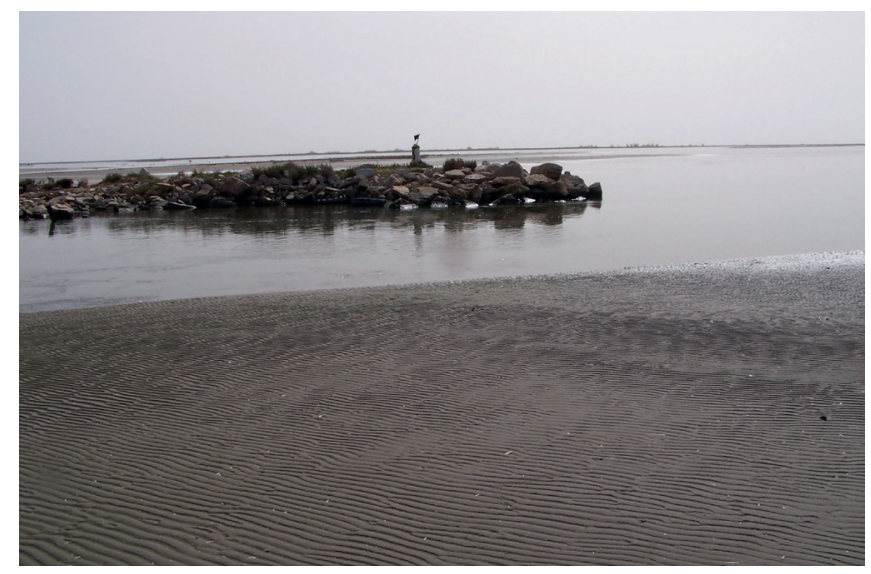

(b)

Fig. 3 Formation of the sandy islet in front of the Eastern Kleisova tidal inlet, which is bounded by jetties, due to sediment accumulation. (a) The process of blockage is almost completed, (b) Detail of the tidal inlet in the vicinity of the jetty, where a small section remains to ensure the communication with the open sea waters

that penetrate into tidal inlets and have thus an effect on the net sediment accumulation affecting the function of the tidal inlets. Therefore, in the present work we focus on the effect of the wind and the tide on the Eastern Kleisova and Tholi tidal inlets.

Based on the above, in the present study, only wind and tide-induced currents are considered. Their characteristics at the nearshore region, which includes the wider area of the tidal inlets and part of the Messolonghi lagoon, can be estimated by application of the MIKE 21 FM (HD \& ST) numerical simulation models [4] [5] [6] to study the hydrodynamic circulation and the associated sediment transport mechanisms. Such a numerical study has been based on previous studies covering the entire area of the Gulf of Patras for wind induced circulation [10], for the barotropic tidal flow [11], but here the emphasis is given on the tidal mouths. Specifically, the locally prevailing winds in the Gulf are NE and SW with a mean value of $6 \mathrm{~m} / \mathrm{s}$ [13] [14] [16], supported by observations during the field campaign of Papailiou [17]. The tidal boundary conditions applied in existing aforementioned studies, were used for the simulations of the Eastern Kleisova and Tholi tidal inlets, in the setup of the numerical model.

\section{Model application}

The numerical modeling system MIKE 21 FM developed by Danish Hydraulic Institute, has been used in the current work to simulate the response of the tidal inlets and the nearshore area in the vicinity of the Eastern Kleisova and Tholi tidal mouths, to the tidal forcing as well as to the forcing of the prevailing winds. This is a fully coupled wave, flow, sediment transport and morphological model complex based on the Finite Volume Method. The unstructured computational mesh is well suited for problems in which high resolution is required in selected areas of the domain; here for instance the narrow tidal inlets and the nearshore region, at the northwestern coasts of the Gulf. For the present study the flow model MIKE $21 \mathrm{HD}$ FM as well as the sediment transport model MIKE 21 ST FM were used, taking into account only the effect of wind and tide induced flow to the resulting hydrodynamics as well as the calculated rates of non-cohesive sediment transport.

A coupled hydrodynamic and sediment transport model requires a much longer timescale than a hydrodynamic model. Specifically, the hydrodynamic phenomena addressed in previous works [11], [12], [15], evolve within a timespan of the order of one week, whereas the sediment transport phenomena addressed in the present paper evolve within a timespan of the order of a month. Therefore, it is the flow model MIKE 21 FM (HD \& ST) that is suitable for the present application.

The simulation of bed evolution has been carried out with Sand Transport (ST) module in Mike 21 Flow Model FM which calculates the sediment transport capacity, the initial rates of bed level changes and the morphological changes for non-cohesive sediment due to currents. In the present formulation, the hydrodynamics are solved at each time step, followed by the sediment transport equations. A new bed level is then computed, and the hydrodynamic model proceeds with the new morphology at the next time step. The solution is based on the sediment continuity equation (Exner equation). The bed is updated continuously through a morphological simulation (at every hydrodynamic time step) based on the estimated bed level change rates [7].

The sediment transport computation is based on hydrodynamics conditions and sediment properties [19]. The sediment type was non-cohesive, with typical properties of quartz sand (mean grain diameter equal to $0.2 \mathrm{~mm}$, and specific gravity equal to 2.65). Both bed and suspended load were taken into account by the model. The first one is controlled by shear stress or stream power per unit and reacts instantaneously with the flow. The second one is characterized by a phase-lag in the transport compared to the flow. Modelling of non-cohesive suspended sediment in a fluid can be described by a transport equation for the volumetric sediment concentration [19]. The Engelund and Hansen [8] total-load transport theory is implemented, while the Meyer-Peter and Muller [15] formula is applied for the calculation of the non-dimensional bed load parameter $\Phi_{b}$ (referred by DHI, [7]). 
Concerning the model validation, the Sand Transport module of Mike 21 Flow Model FM has been successfully validated by predicting the equilibrium slope of a straight flume [7].

For the numerical simulations presented below an unstructured mesh was used, which covers the entire Gulf of Patras and part of the Messolonghi lagoon. The numerical domain used in the simulations contains two open boundaries, located at the same sites as in the domain used by Fourniotis and Horsch [10], and Horsch and Fourniotis [12], for the simulation of the barotropic wind and tide-induced flow in the Gulf of Patras, that is one at the entrance of the Gulf of Patras from the Ionian Sea, and the other at the end of the Gulf of Patras entrance to the Gulf of Corinth. The western open boundary is located approximately $15 \mathrm{~km}$ from the study area of Tholi and $32 \mathrm{~km}$ far from the study area of Kleisova. The eastern open boundary is approximately $54 \mathrm{~km}$ far from the study area of Tholi and $40 \mathrm{~km}$ far from the study area of Kleisova. The computational domain was chosen so as to ensure that the areas of interest, i.e. the vicinity of tidal inlets, would not be affected by boundary effects. Triangular elements of variable size were used to discretize the domain and to obtain adequate resolution in the aforementioned areas of particular interest, as well as at the nearshore region of the northwestern coasts of the Gulf, where the $12 \mathrm{~km}$ long sand bar is located. A detail of the model mesh focusing on the areas of particular interest is shown in Fig. 4. A progressive mesh refinement is implemented in the vicinity of the tidal inlets in order to study in detail the flow structure and sediment motion.
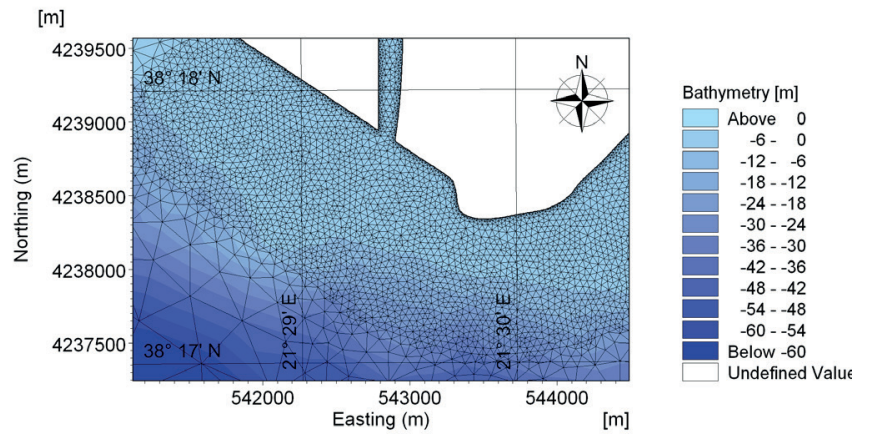

(a)

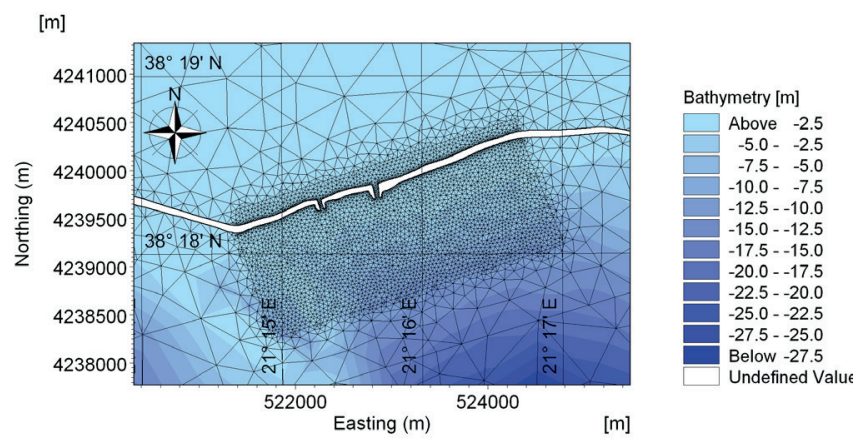

(b)

Fig. 4 Mesh details close to tidal inlets of (a) Eastern Kleisova, (b) Tholi, respectively, showing the degree of refinement of mesh elements in areas of particular interest. Superimposed is the unstructured triangular mesh as well as the bathymetric map of the area. The coordinate system refers to UTM-34.
The numerical representation of the coastline and the bathymetry of the Gulf and the lagoon were based on digital maps of the Hellenic Navy Hydrographic Service. From these maps, the ASCII files, required for the mesh generation of the hydrodynamic code, MIKE 21 HD FM, were produced using a GIS module, which was also used to convert the digital data to the appropriate UTM-34 zone projection.

The boundary and initial conditions used in the present study are identical to those applied in [12] [18], for simulation of the barotropic, wind and tide-induced circulation in the same computational domain. These models cover the whole area of the Gulf and have been validated using available field measurements.

\section{Results and discussion}

In the present section we briefly summarize numerical predictions of the hydrodynamic circulation and the sediment transport with emphasis on the vicinity of Eastern Kleisova and Tholi, tidal inlets. To obtain these results the modeling system was considered being fully driven by wind and tidal forcing only. This means that the model does not account for breaking waves forcing, since the effect of wave induced currents on longshore sediment transport examined in a previous work [3]. Our aim is to describe the hydrodynamic regime during the flood or ebb tide in the vicinity of the tidal inlets and obtain information about the related sediment transport and the resulting bed formation, i.e. bed level change/evolution and total sediment load accumulation. The monthly sediment accumulation is calculated using the locally prevailing winds, i.e. NE and SW, as well as the tidal regime of the Gulf, for both the Eastern Kleisova and Tholi, respectively. Results are given at the end of one month simulation.

Moreover, simulations for a 6 months period, i.e. from 01-102008 to 27-03-2009, were conducted based on real wind data records available from the station of the Management Body of Messolonghi lagoon. It is noteworthy that from $03-11-2008$ to 04-11-2008 a severe storm event occurred which was associated with severe sedimentation at the mouths of the tidal inlets of the lagoon. Fig. 5 shows the wind direction and wind speed used for a specific run covering the above mentioned period of time. It should be noted that the wind data records are applied as a uniform wind field all over the computational domain.

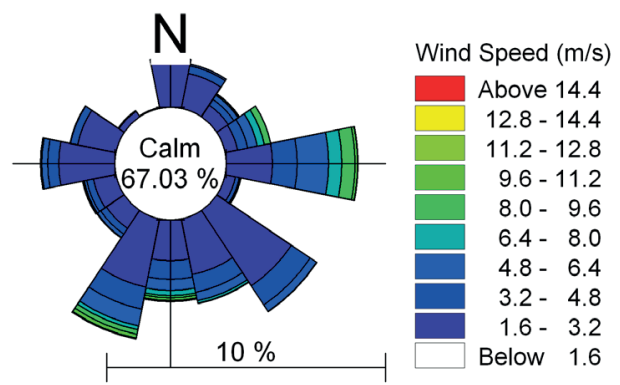

Fig. 5 Wind rose for the station of the Management Body of Messolonghi Lagoon, used in numerical simulations 
In all cases examined, a computational domain and an initial bathymetry were created using the bed levels, i.e. the bathymetry, from maps of the Hellenic Navy Hydrographic Service. Specifically, the bathymetry shown in Fig. 3 was used as the initial bathymetry for the simulation of bed level changes over the simulation period. To ensure brevity, only model results obtained from the simulation of one month, in real time, are presented and discussed in the following paragraphs.

Based on the numerical simulations it is found that under the combined action of tide and the prevailing winds in the wider area of the Gulf of Patras, i.e. SW or NE, characteristic flow circulation regimes and bed formations appear. Specifically, the SW wind causes sediment accumulation behind the tidal inlets, in the interior of the lagoon, for the case of Tholi's tidal inlet (Fig. 6a). On the contrary, sediment accumulation occurs in front of the tidal mouth, at the northwestern shoals of the Gulf; under the effect of NE wind (Fig. 6b). It is worth noting that no substantial accumulation was computed in the Eastern Kleisova tidal inlet under the effect of a constant wind.

The effect of an unsteady wind to the sedimentation at the tidal inlets reveals a different bed level formation. Based on the numerical simulations, the cyclonic and anti-cyclonic eddies which have been found to form in the vicinity of the tidal mouths, are the dominant sedimentation mechanisms, for the case of Eastern Kleisova and Tholi. Fig. 7 depicts the simulated water currents at Tholi tidal inlet for ebb (Fig. 7a) and flood (Fig. 7b), conditions and the corresponding currents in front of the mouth of Eastern Kleisova (Fig. 7c). It is noteworthy that the predicted ebb currents near and inside the tidal inlet overwhelms the flood currents.

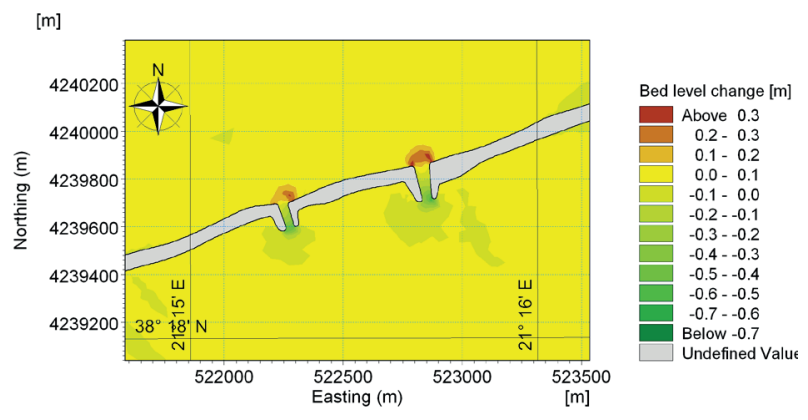

(a)

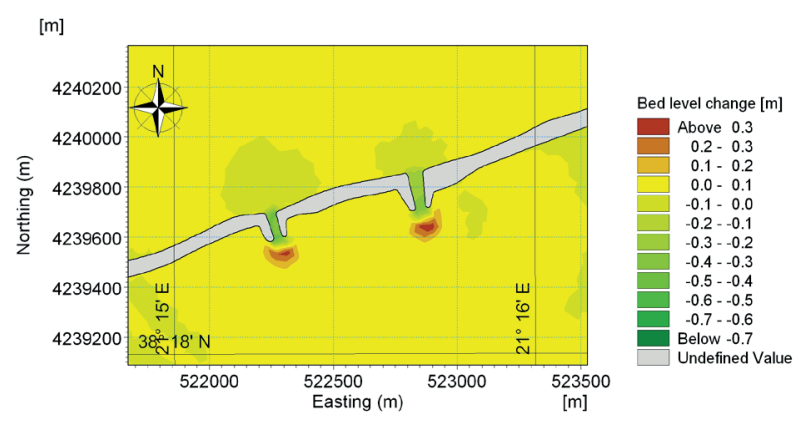

(b)

Fig. 6 Computed bed level change for the case of Tholi's tidal inlet under the effect of (a) SW and (b) NE wind
Under the locally prevailing hydrodynamic regime, sedimentation occurs in front and inside of the mouth of the tidal inlet. The mechanism that causes the sedimentation is as follows: under the effect of the strong eddies, that form at the near tip area of the jetties, the accumulated sediment - in the region westwards of the jetties - gradually escapes from the upstream (western) region, recirculates and, eventually, part of the total transported sediment accumulates in front of the mouth. Then, the tidal current during the flood tide drives the sediment inside the tidal channel. Thus, the water depth becomes shallow and the exchange flowrate is impeded.

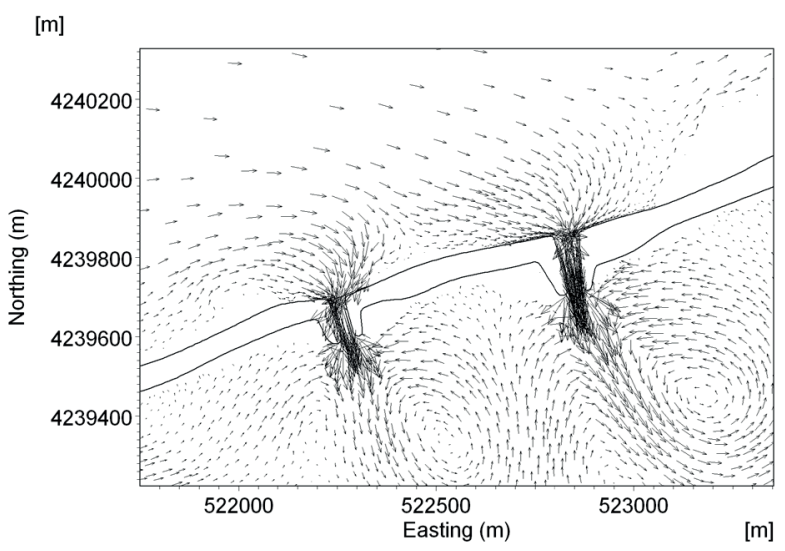

(a)

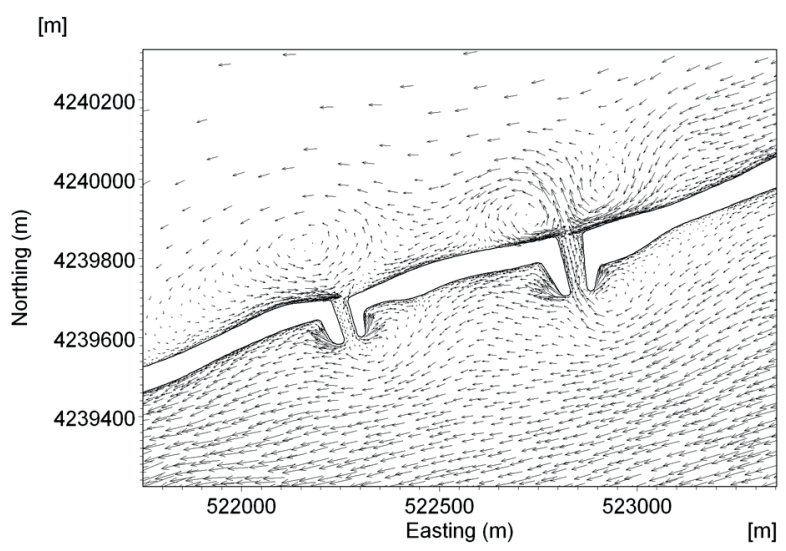

(b)

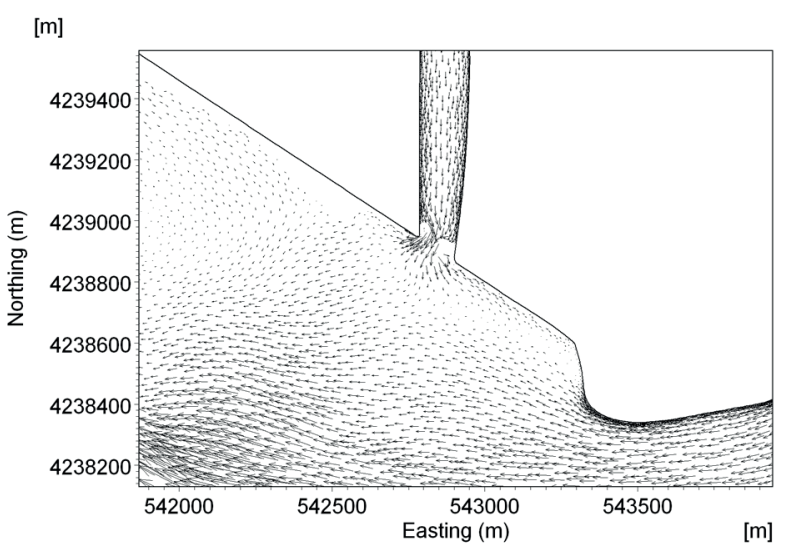

(c)

Fig. 7 Simulated (a) ebb and (b) flood currents in the vicinity of the Tholi tidal inlet, and (c) at the Eastern Kleisova 
This mechanism can be qualitatively confirmed by means of satellite images from Google Earth. In Fig. 8 the sequence of events leading to the formation of sandy islet in front or inside the tidal inlet is inferred from simple inspection. Specifically, accretion of sediment starts from the west and extends up to the tip of the jetty, since the presence of jetties trap the sediment westward. Under the influence of the vortices forming at the near tip area of the jetties, a portion of the transported sediment moves, recirculates, and gradually is trapped in front of the mouth, while deposition of sediment is observed to occur in front and inside of the tidal mouth causing gradually shoaling. The ingress of sediments into the entrance of the inlet leads to constriction which commonly results in clogging of the tidal mouth.

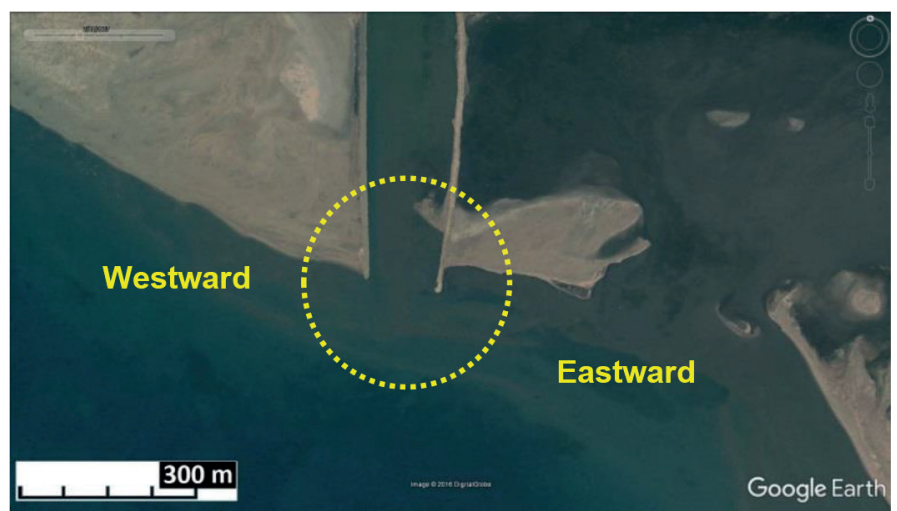

(a)

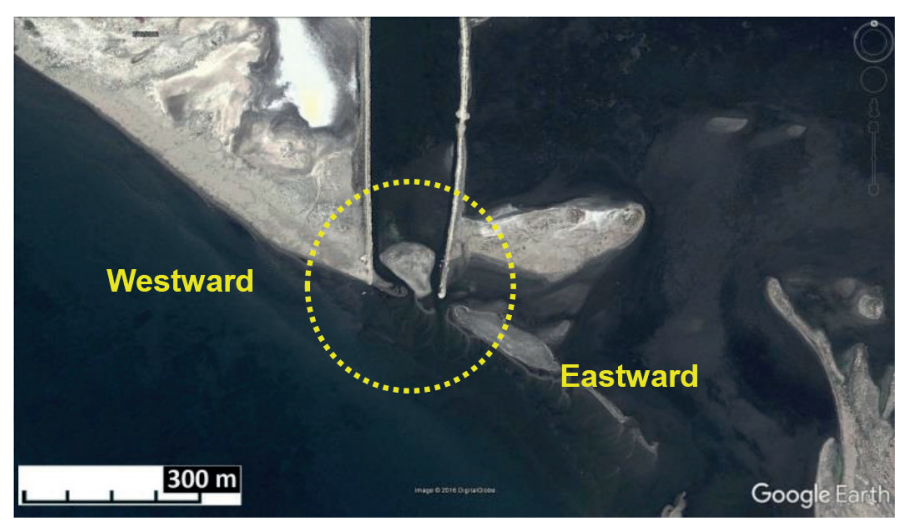

(b)

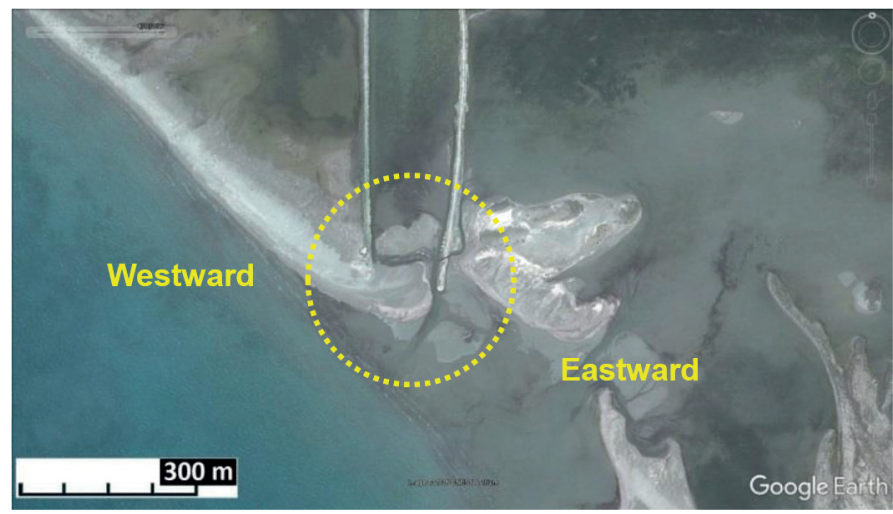

(c)

Fig. 8 The sequence of events leading to the formation of the sandy islet in front and inside the tidal inlet, for the case of Eastern Kleisova. Satellite images from Google Earth, (a) 2007, (b) 2012, (c) 2016 [9].
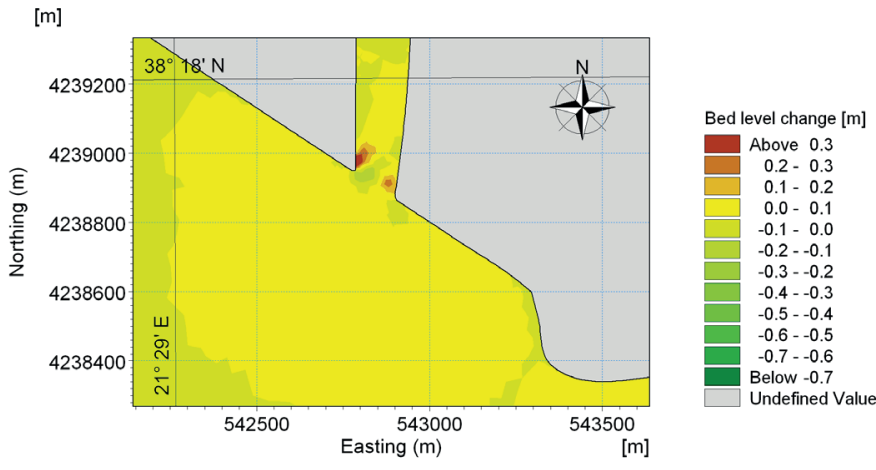

(a)
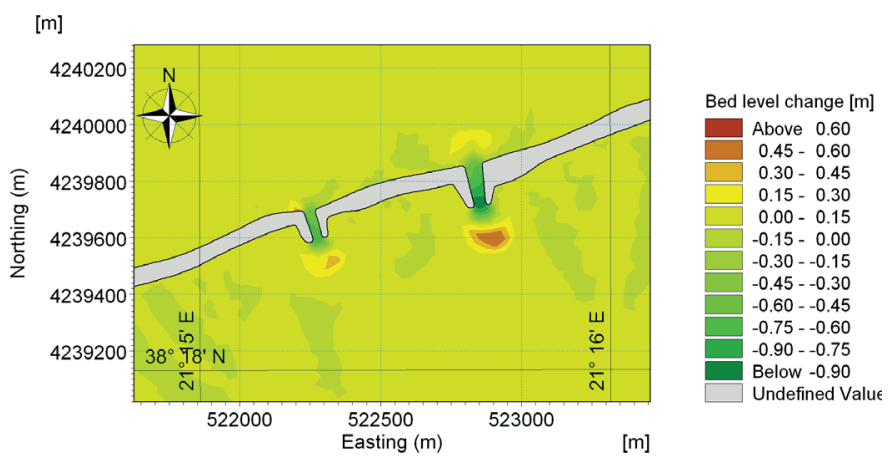

(b)
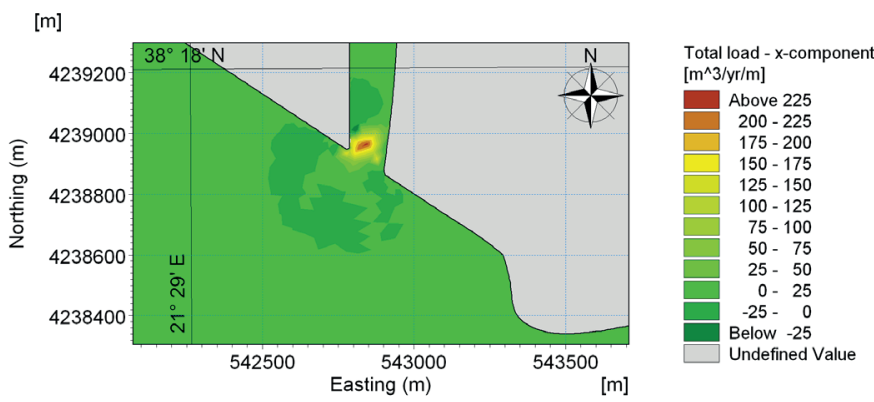

(c)
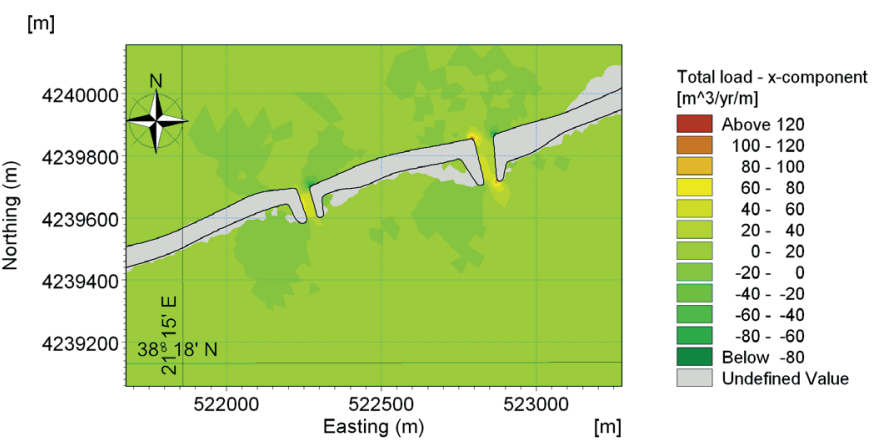

(d)

Fig. 9 Simulated bed level change $(a, b)$ and total sediment load accumulation $(c, d)$ in the vicinity of Eastern Kleisova and Tholi tidal inlets.

According to the numerical simulations, a bed level change of the order of $0.30 \mathrm{~m}-0.60 \mathrm{~m}$ in front or inside of the tidal mouths results within a month, which contains the severe storm event mentioned above. Specifically, under the combined action of the tide and the wind, a sandy islet is formed in front or behind the tidal inlets shoaling thus gradually the mouths (Fig. 9a, b). Based on the numerical simulations, it follows that part of transported sediment is approximately accumulated in 
the time scale of the order of one (1) month, with rates of total loads of sand equal to $200 \mathrm{~m}^{3} / \mathrm{y} / \mathrm{m}$ and $80-100 \mathrm{~m}^{3} / \mathrm{y} / \mathrm{m}$, for the case of Eastern Kleisova and Tholi, respectively (Fig. 9c, d). The accumulated sand leads to an increment of bed level and gradually progresses into the tidal channels. Under these conditions, the sedimentation in the area just outside of the tidal mouth, results in depths less than the desired channel depths of $\sim 1 \mathrm{~m}$. This in turn leads to constriction of the cross section of the inlet and causes water quality problems in the lagoon. The problem becomes more acute if the entrances remain closed for an extended period of time. Dredging is then required in order to ensure the effective function of the tidal inlets.

\section{Conclusions}

Based on the numerical predictions for sediment transport, bed level evolution and total sediment load accumulation, which have been qualitatively corroborated by satellite images from Google Earth, it has been shown that in all cases examined, the potential of inlets to trap sand of the littoral system in their flood and ebb shoals is present. Further, the accumulated sediment upstream (westwards) of the jetties moves in front of the tidal mouth, causing sedimentation and gradually shoaling, under the influence of local hydrodynamics associated with vortices forming at the near tip area of the jetties.

The numerical results lead to recommendations of soft and relatively cheap solutions with minimum impact to the sandy barrier zone, namely, regular maintenance, i.e. dredging of the upstream area. Dredging should be also performed along the tidal channel, in front of the mouth and in the back of the channel inside the lagoon, until the dredged depth "meets" the same isobaths in the open sea and in the lagoon, respectively.

Sound management requires further that the excavated sand should be used for beach nourishment downstream of the nearby jetty (eastwards of the mouth) so that the material is recycled. In this frame, the desired depth at the mouths can be maintained and the exchange flow between the lagoon and the Gulf of Patras can be kept as natural as possible.

\section{Acknowledgements}

Partial funding of the present study by the Management Body of the Messolonghi Lagoon, Aitoloakarnania is gratefully acknowledged.

\section{References}

[1] Bruun, P., Gerritsen, F. "Stability of Coastal Inlets". Coastal Engineering Proceedings, 7, pp. 386-417. https://doi.org/10.9753/icce.v7.23

[2] Bruun, P. "Tidal inlets on alluvial shores". In: Lagunas Costeras. (Castanares, A .A., Phleger, F. B. (eds.)). UN Simposio UNAM-UNESCO. Vol. 1, pp. 349-366. 1969.
[3] Fourniotis, N., Th., Horsch, G. M., Leftheriotis, G. A. "Simulation of longshore sediment transport and coastline change in the vicinity of two fishery tidal inlets of Messolonghi - Aetoliko lagoon complex". ISOPE-2016 Conference, The $26^{\text {th }}$ International Ocean and Polar Engineering Conference, 26 June 2 July, Rhodes, Greece, pp. 1255-1260. 2016. http:// www.isope.org/publications/proceedings/ISOPE/ISOPE\%202016/papers/16TPC-1227.pdf

[4] DHI. "Mike 21 Flow Model FM, HydrodynamicModule". UserGuide. 2009.

[5] DHI. "Mike 21 Flow Model FM, Sand TransportModule". UserGuide 2009.

[6] DHI. "MIKE ZERO, Preprocessing and postprocessing". Volume 1, 2, User Guide. 2009.

[7] DHI Software. MIKE21 and MIKE 3 Flow Model FM: Sand Transport Module, Scientific Documentation, Danish Hydraulic Institute, Horsholm, Denmark. 2014.

[8] Engelund, F., Fredsee, J. "A Monograph on Sediment Transport in Alluvial Channels". Nordic Hydrology, 7, pp. 293-306. 1976.

[9] Google Earth Pro (Version 7.3.0.3830) [Computer program]. Available at http://www.google.com/earth/download/ge/agree.html (Accessed 02 August 2017)

[10] Fourniotis, N. Th., Horsch, G. M. "Three-dimensional numerical simulation of wind-induced barotropic circulation in the Gulf of Patras." Ocean Engineering, 37 (4), pp. 355-364. 2010. https://doi.org/10.1016/j.oceaneng.2010.01.002

[11] Fourniotis, N. Th., Horsch, G. M. "Baroclinic circulation in the Gulf of Patras (Greece)" Ocean Engineering, 104, pp. 238-248. 2015. https://doi.org/10.1016/j.oceaneng.2015.04.080

[12] Horsch, G. M., Fourniotis, N. Th. "Wintertime Tidal Hydrodynamics in the Gulf of Patras, Greece." Journal of Coastal Research, 2017, 33(6), pp. 1305-1314. 2017. https://doi.org/10.2112/jcoastres-d-16-00133.1

[13] Ilias, D. I. Monthly Bulletin of the Laboratory of Atmospheric Physics, University of Patras, Patras, Greece, p. 432. 1973.

[14] Ilias, D. I. "Some meteorological and climatological data from the area of the crossing". In: The Rion-Antirion Crossing. (Goudas, K. (Ed.)), Patras, Greece, (in Greek) 1978.

[15] Meyer-Peter, E., Müller, R. "Formulas for bed load transport". In: Proceedings of 2nd meeting of the International Assiciation for Hydraulic Structures Research, Deft, 7 June 1948. pp. 39-64.

[16] Piper, D. J. W., Panagos, A. G., Kontopoulos, N., Spiliotopoulou, M. "Coastal processes and morphology, Gulf of Patras, Greece". Zeitschrift fur Geomorphologie N.F., 26(3), pp. 365-374. 1982.

[17] Papailiou, D., D. "Oceanographical Study in Patras Gulf Waters for Pollution Management". Volume 2. Patras, Greece: University of Patras, Department of MechanicalEngineering, 161p. [inGreek]. 1982.

[18] Fourniotis, N., Th., Horsch, G. M. "Modeling Wind and Tide-Induced Currents In The Eastern Ionian Sea: Patraikos Gulf (Greece)", In. Proceedings of 16th IAHR-APD Congress and 3rd Symposium of IAHR-ISHS, 20-23 October, Hohai University, Nanjing, China, pp. 1201-1206. 2008. https://doi.org/10.1007/978-3-540-89465-0_209

[19] Zavattero, E., Du, M., Ma, Q., Delestre, O., Gourbesville, P. "2D sediment transport modelling in high energy river-application to Var river, France". Procedia Engineering, 154, pp. 536-543. 2016. https://doi.org/10.1016/j.proeng.2016.07.549 